\title{
Approximate Solution of Nonlinear System of BVP Arising in Fluid Flow Problem
}

\author{
A. K. Alomari, ${ }^{1}$ N. Ratib Anakira, ${ }^{2}$ A. Sami Bataineh, ${ }^{3}$ and I. Hashim ${ }^{2}$ \\ ${ }^{1}$ Department of Mathematics, Faculty of Science, Hashemite University, Zarqa 13115, Jordan \\ ${ }^{2}$ School of Mathematical Sciences, Universiti Kebangsaan Malaysia, 43600 Bangi, Selangor, Malaysia \\ ${ }^{3}$ Department of Mathematics, Faculty of Science, Al-Balqa' Applied University, Salt 19117, Jordan
}

Correspondence should be addressed to A. K. Alomari; abdomari2008@yahoo.com

Received 15 December 2012; Accepted 7 April 2013

Academic Editor: Alexei Mailybaev

Copyright (C) 2013 A. K. Alomari et al. This is an open access article distributed under the Creative Commons Attribution License, which permits unrestricted use, distribution, and reproduction in any medium, provided the original work is properly cited.

\begin{abstract}
We extend for the first time the applicability of the Optimal Homotopy Asymptotic Method (OHAM) to find approximate solution of a system of two-point boundary-value problems (BVPs). The OHAM provides us with a very simple way to control and adjust the convergence of the series solution using the auxiliary constants which are optimally determined. Comparisons made show the effectiveness and reliability of the method.
\end{abstract}

\section{Introduction}

Many real-world problems can be modelled by nonlinear differential equations. For example, fluid flow problems can give rise to boundary-value problems (BVPs) or systems of BVPs with conditions specified at two or more different points. Finding a reliable method for solving BVPs is of great interest. Noor and Mohyud-Din [1-3] presented approximate solutions of some classes of BVPs by using the variational iteration method (VIM), homotopy perturbation method (HPM), and variational iteration decomposition method (VIDM). Herisanu et al. [4] developed the so-called Optimal Homotopy Asymptotic Method (OHAM) for solving nonlinear problems. OHAM provides us with a very simple way to control and adjust the convergence of the series solution using the auxiliary constants which are optimally determined. Several promising applications of OHAM to problems in fluid dynamics have been presented [5-12]. Ali et al. $[13,14]$ solved several two-point and multipoint BVPs by OHAM. Very recently, Hashmi et al. [15] applied OHAM for finding the approximate solutions of a class of Volterra integral equations with weakly singular kernels.

The laminar fully developed combined free and forced magnetoconvection in a vertical channel with symmetric and asymmetric boundary heatings in the presence of viscous and
Joulean dissipations was studied by Umavathi and Malashetty [16]. The mathematical model describing the channel flow problem is governed by a system of nonlinear BVPs. Umavathi and Malashetty [16] employed the classical perturbation technique to solve the system of BVPs. The aim of the present work is thus to propose an accurate approach to the channel flow problem using an analytical technique, namely, OHAM. The efficiency of the procedure is based on the construction and determination of the auxiliary functions combined with a convenient way to optimally control the convergence of the solution.

\section{The Model Equation}

The system of BVPs modelling the channel flow problem as given in [16] is

$$
\begin{gathered}
\frac{d^{4} u}{d y^{4}}-M^{2} \frac{d^{2} u}{d y^{2}}=M^{2} G R B r u^{2}+G R B r\left(\frac{d u}{d y}\right)^{2}, \\
\frac{d^{2} \theta}{d y^{2}}=-M^{2} B r u^{2}-B r\left(\frac{d u}{d y}\right)^{2},
\end{gathered}
$$


subject to

$$
\begin{gathered}
u\left(-\frac{1}{4}\right)=u\left(\frac{1}{4}\right)=0, \\
\left.\frac{d^{2} u}{d y^{2}}\right|_{y=-1 / 4}=-48+\frac{R_{T} G R}{2}, \\
\left.\frac{d^{2} u}{d y^{2}}\right|_{y=1 / 4}=-48-\frac{R_{T} G R}{2}, \\
\theta\left(-\frac{1}{4}\right)=-\frac{R_{T}}{2}, \quad \theta\left(\frac{1}{4}\right)=\frac{R_{T}}{2},
\end{gathered}
$$

where the parameter $R_{T}$ becomes one for asymmetric heating and zero for symmetric heating. The special case $B r=0$ was solved exactly by Umavathi and Malashetty [16], and the exact solutions are

$$
\begin{gathered}
u=\frac{48}{M^{2}}\left(1-\frac{\cosh (M y)}{\cosh (M / 4)}\right) \\
+\frac{2 G R R_{T}}{M^{2}}\left(y-\frac{\sinh (M y)}{4 \sinh (M / 4)}\right), \\
\theta=2 R_{T} y .
\end{gathered}
$$

where

$$
\begin{aligned}
& A=-\frac{1152 B r}{M^{2}}, \\
& B=-\frac{576 B r}{M^{4} \cosh ^{2}(M / 4)}, \\
& C=-\frac{4608 B r}{M^{4} \cosh (M / 4)} .
\end{aligned}
$$

We remark that the general case of both $B r \neq 0$ and $G R \neq 0$ is very difficult to solve exactly. For this case, Umavathi and Malashetty [16] have given the standard perturbation solutions by assuming $\varepsilon=B r G R$ to be the small parameter in the expansion.

\section{Basic Idea of OHAM}

Consider the following differential equations:

$$
\begin{gathered}
L(u(y))+g(y)+N(u(y))=0, \\
B\left(u, \frac{d u}{d y}\right)=0,
\end{gathered}
$$

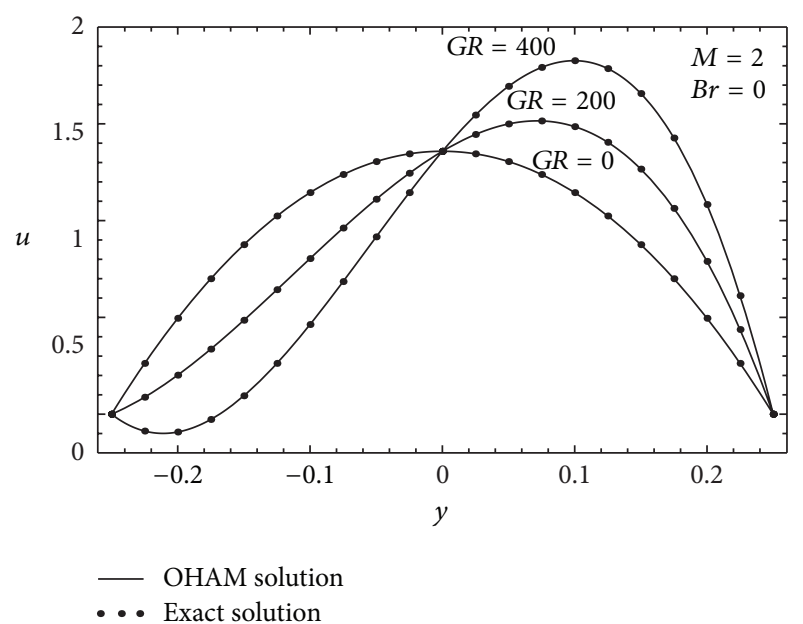

FIgURE 1: Plots of $u$ and versus $y$ in the case of asymmetric heating for different values of $G R$ and $B r=0, M=2$.

where $L$ is a linear operator, $N$ is a nonlinear operator, $u(y)$ is an unknown function, $y$ denotes independent variable, $g(y)$ is a known function, and $B$ is a boundary operator.

According to the basic idea of OHAM [4-6], we construct a homotopy $h(v(y, p), p): R \times[0,1] \rightarrow R$ which satisfies

$$
\begin{gathered}
(1-p)[L(v(y, p))+g(y)] \\
=H(p)[L(v(y, p))+g(y)+N(v(y, p))], \\
B\left(v(y, p), \frac{\partial v(y, p)}{\partial y}\right)=0,
\end{gathered}
$$

where $y \in R$ and $p \in[0,1]$ is an embedding parameter, $H(p)$ is a nonzero auxiliary function for $p \neq 0, H(0)=0$ and $v(y, p)$ is an unknown function. Obviously, when $p=0$ and $p=1$ it holds that $v(y, 0)=u_{0}(y)$ and $v(y, 1)=u(y)$, respectively. Thus, as $p$ varies from 0 to 1 , the solution $v(y, p)$ approaches from $u(y)$ to $u_{0}(y)$, where $u_{0}(y)$ is obtained from (7) for $p=$ 0 , and we have

$$
L\left(u_{0}(y)\right)+g(y)=0, \quad B\left(u_{0}, \frac{d u_{0}}{d y}\right)=0 .
$$

Next, we choose auxiliary function $H(p)$ in the form

$$
H(p)=p C_{1}+p^{2} C_{2}+p^{3} C_{3}+\cdots,
$$

where $C_{1}, C_{2}, C_{3}, \ldots$ are constants to be determined, and $H(p)$ can be expressed in many forms as reported in [4-7].

To get an approximate solution, we expand $v\left(y, p, C_{i}\right)$ in Taylor's series about $p$ in the following manner:

$$
v\left(y, p, C_{i}\right)=u_{0}(y)+\sum_{k=1}^{\infty} u_{k}\left(y, C_{1}, C_{2}, \ldots, C_{k}\right) p^{k}
$$

Substituting (11) into (7) and equating the coefficient of the like powers of $p$, we obtain the following linear equations. 
The zeroth-order problem is given by (9), and the first- and second-order problems are given as

$$
\begin{gathered}
L\left(u_{1}(y)\right)=C_{1} N_{0}\left(u_{0}(y)\right), \quad B\left(u_{1}, \frac{d u_{1}}{d y}\right)=0 \\
L\left(u_{2}(y)\right)-L\left(u_{1}(y)\right)=C_{2} N_{0}\left(u_{0}(y)\right)+C_{1} \\
\times\left[L u_{1}(y)+N_{1}\left(u_{0}(y), u_{1}(y)\right)\right], \\
B\left(u_{2}, \frac{d u_{2}}{d y}\right)=0 .
\end{gathered}
$$

And the general governing equations for $u_{k}(y)$ are given as

$$
\begin{gathered}
L\left(u_{k}(y)\right)-L\left(u_{k-1}(y)\right) \\
=C_{k} N_{0}\left(u_{0}(y)\right)+\sum_{i=1}^{k-1} C_{i}\left[L\left(u_{k-i}(y)\right)+N_{k-i}\left(u_{0}(y),\right.\right. \\
\left.\left.u_{1}(y), \ldots, u_{k-1}(y)\right)\right], \\
B\left(u_{k}, \frac{d u_{k}}{d y}\right)=0,
\end{gathered}
$$

where $k=2,3, \ldots$ and $N_{m}\left(u_{0}(y), u_{1}(y), \ldots, u_{m}(y)\right)$ is the coefficient of $p^{m}$ in the expansion of $N(v(y, p))$ about the embedding parameter $p$

$$
\begin{aligned}
N\left(v\left(y, p, C_{i}\right)\right)= & N_{0}\left(u_{0}(y)\right) \\
& +\sum_{m=1}^{\infty} N_{m}\left(u_{0}(y), u_{1}(y), \ldots, u_{m}(y)\right) p^{m} .
\end{aligned}
$$

It has been observed that the convergence of the series (11) depends upon the auxiliary constants $C_{1}, C_{2}, C_{3}, \ldots$ If the series is convergent at $p=1$, one has

$$
v\left(y, C_{i}\right)=u_{0}(y)+\sum_{k=1}^{\infty} u_{k}\left(y, C_{1}, C_{2}, \ldots, C_{k}\right) .
$$

The results of the $m$ th-order approximations are

$$
\begin{aligned}
\tilde{u} & \left(y, C_{1}, C_{2}, C_{3}, \ldots, C_{m}\right) \\
& =u_{0}(y)+\sum_{i=1}^{m} u_{i}\left(y, C_{1}, C_{2}, \ldots, C_{i}\right) .
\end{aligned}
$$

Substituting (16) into (6) it results the following residual:

$$
\begin{aligned}
R\left(y, C_{1}, C_{2}, C_{3}, \ldots, C_{m}\right)= & L\left(\tilde{u}\left(y, C_{1}, C_{2}, C_{3}, \ldots, C_{m}\right)\right)+g(y) \\
& +N\left(\tilde{u}\left(y, C_{1}, C_{2}, C_{3}, \ldots, C_{m}\right)\right) .
\end{aligned}
$$

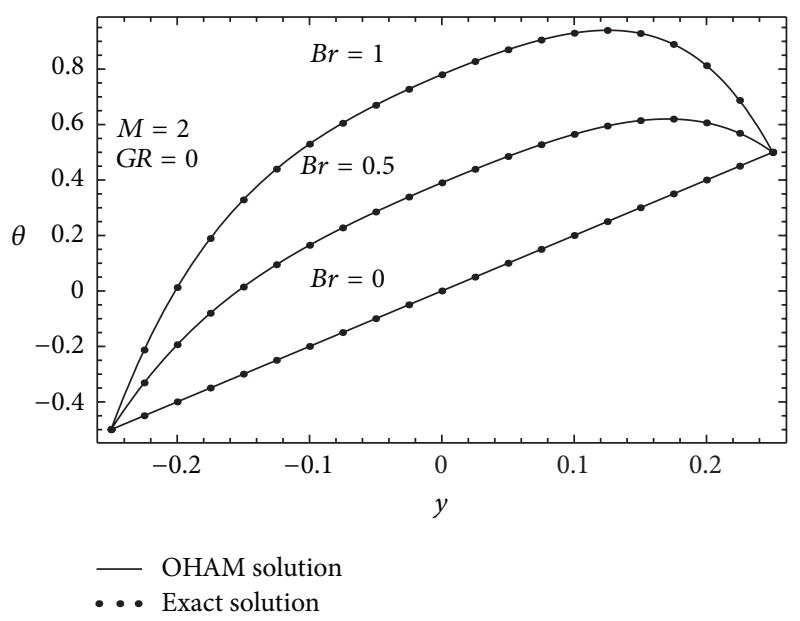

Figure 2: Plots of $\theta$ versus $y$ in the case of asymmetric heating for different values of $B r$ and $G R=0, M=2$.

If $R=0$, then $\tilde{u}$ will be the exact solution. Generally this does not happen, especially in nonlinear problems. In order to find the optimal values of $C_{i}, i=1,2,3, \ldots$, we first construct the functional

$$
J\left(C_{1}, C_{2}, C_{3}, \ldots, C_{m}\right)=\int_{a}^{b} R^{2}\left(y, C_{1}, C_{2}, C_{3}, \ldots, C_{m}\right) d y,
$$

and then minimizing it, we have

$$
\frac{\partial J}{\partial C_{1}}=\frac{\partial J}{\partial C_{2}}=\cdots=\frac{\partial J}{\partial C_{m}}=0
$$

where $a$ and $b$ are in the domain of the problem. With these constants known, the approximate solution (of order $m$ ) is well determined.

3.1. Application of OHAM. In this section, we apply OHAM for solving the nonlinear system of two-point BVP (1)-(2). By applying the proposed method, the zeroth-order deformation equation is

$$
\begin{aligned}
& (1-p) L\left[\tilde{u}(y, p)-u_{0}(y)\right] \\
& \quad=H\left(p, C_{i}\right)[N(\widetilde{u}(y, p))], \\
& (1-p) L\left[\tilde{\theta}(y, p)-\theta_{0}(y)\right] \\
& \quad=H\left(p, C_{j}\right)[N(\widetilde{\theta}(y, p), \tilde{u}(y, p))],
\end{aligned}
$$

subject to the boundary conditions

$$
\begin{array}{cc}
\tilde{u}\left(-\frac{1}{4}, p\right)=0, & \tilde{u}\left(\frac{1}{4}, p\right)=0 \\
\tilde{u}^{\prime \prime}\left(-\frac{1}{4}, p\right)=-48+\frac{R_{T} G R}{2}, & \tilde{u}^{\prime \prime}\left(\frac{1}{4}, p\right)=-48-\frac{R_{T} G R}{2}, \\
\tilde{\theta}\left(-\frac{1}{4}, y\right)=-\frac{R_{T}}{2}, & \tilde{\theta}\left(\frac{1}{4}, y\right)=\frac{R_{T}}{2} .
\end{array}
$$


TABLE 1: Optimal values of $C_{i}$ for the case $M=2$ and different values of $G R$ and $B r$.

\begin{tabular}{lcccc}
\hline$B r$ & $G R$ & $C_{1}$ & $C_{2}$ & $C_{3}$ \\
\hline 0 & 400 & -0.96436 & -0.00133 & 0.00005 \\
$8 / 100$ & 100 & -1.11947 & -0.01693 & -0.00181 \\
0 & 0 & -0.96436 & -0.00133 & 0.00005 \\
$8 / 500$ & 500 & -1.19429 & -0.07113 & -0.01860 \\
1 & 0 & -0.96439 & -0.00133 & 0.00005 \\
$8 / 100$ & -100 & -0.80026 & -0.02050 & 0.00140 \\
0 & \pm 100 & -0.95976 & -0.00116 & 0.00003 \\
0 & \pm 500 & -0.95976 & -0.00116 & 0.00003 \\
$8 / 500$ & -500 & -0.79213 & -0.02725 & 0.00383 \\
\hline
\end{tabular}

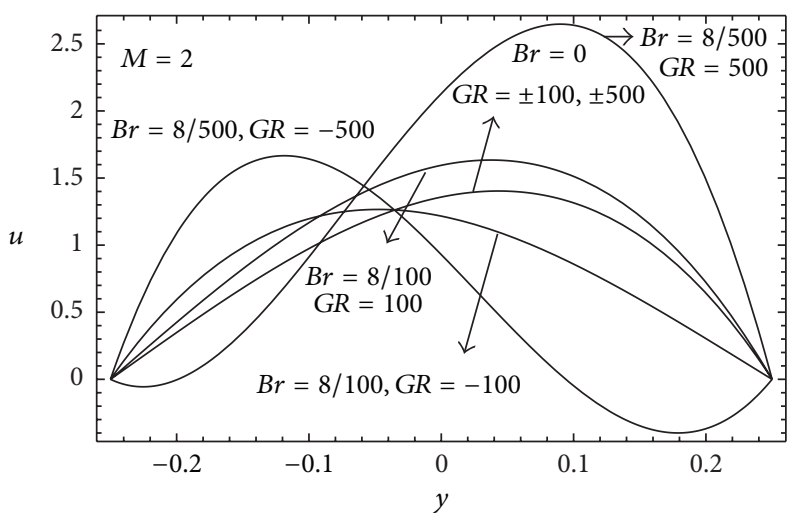

(a)

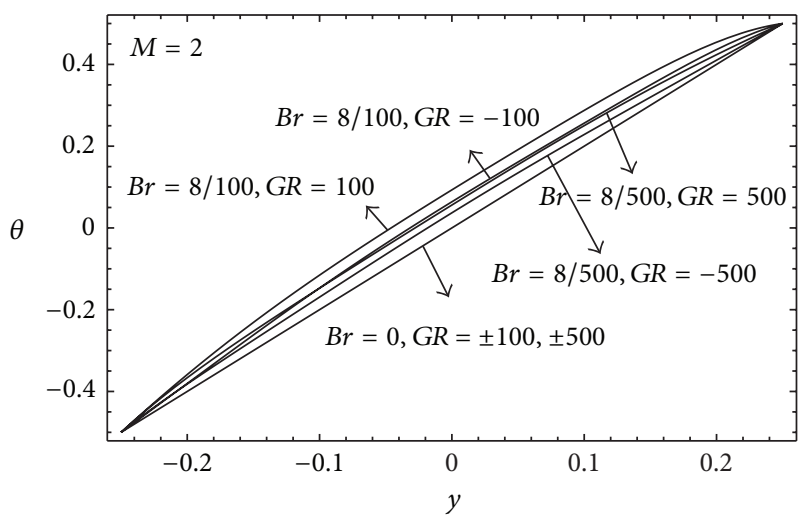

(b)

FIGURE 3: Plots of (a) $u$ and (b) $\theta$ versus $y$ in the case of asymmetric heating for different values of $B r$ and $G R$.

Using the framework of OHAM the $m$ th-order

$$
L_{1}\left[\tilde{u}-\chi_{m} u_{m-1}\right]=R_{1, m}\left(C_{i}, \vec{u}_{m-1}\right),
$$

where $\vec{u}_{m-1}=\left\{u_{0}, u_{1}, \ldots, u_{m-1}\right\}$,

$$
\begin{aligned}
R_{1, m}= & \sum_{i=0}^{m-1} C_{i+1} u_{m-1-i}^{(4)}-M^{2} \operatorname{GRBr} \sum_{i=0}^{m-1} u_{m-1-i} \\
& \times \sum_{j=0}^{i} C_{j+1} u_{j-i}-G R B r \sum_{i=0}^{m-1} u_{m-1-i}^{\prime} \sum_{j=0}^{i} C_{j+1} u_{j-1}^{\prime}, \\
& L_{2}\left[\tilde{\theta}_{m}-\chi_{m} \theta_{m-1}\right]=R_{2, m}\left(C_{i}, \vec{\theta}_{m-1}\right)
\end{aligned}
$$

$$
\times \sum_{j=0}^{i} C_{i+1} u_{j-i}+B r \sum_{i=0}^{m-1} u_{m-1-i}^{\prime} \sum_{j=0}^{i} C_{i+1} u_{j-1}^{\prime} .
$$

Now the zeroth-order problem is

$$
\begin{aligned}
& u_{0}^{(4)}(y)=0, \\
& \theta_{0}^{\prime \prime}(y)=0,
\end{aligned}
$$

subject to the boundary conditions

$$
\begin{gathered}
u_{0}\left(-\frac{1}{4}\right)=0, \quad u_{0}\left(\frac{1}{4}\right)=0, \\
u_{0}^{\prime \prime}\left(-\frac{1}{4}\right)=-48+\frac{R_{T} G R}{2}, \\
u_{0}^{\prime \prime}\left(\frac{1}{4}\right)=-48-\frac{R_{T} G R}{2}, \\
\theta_{0}\left(-\frac{1}{4}\right)=-\frac{R_{T}}{2}, \quad \theta_{0}\left(\frac{1}{4}\right)=\frac{R_{T}}{2} .
\end{gathered}
$$

The solutions are

$$
\begin{gathered}
u_{0}(y)=\frac{1}{48}\left(72-1152 y^{2}+y R_{T} G R-16 y^{3} R_{T} G R\right), \\
\theta_{0}(y)=2 y R_{T} .
\end{gathered}
$$

Now the first-order problem is

$$
\begin{aligned}
& u_{1}^{(4)}\left(y, C_{1}\right)=-C_{1} M^{2} \operatorname{Br} G R u_{0}^{2}(y)-C_{1} \operatorname{Br} G R\left(u_{0}^{\prime}(y)\right)^{2} \\
&-C_{1} M^{2} u_{0}^{\prime \prime}(y)+C_{1} u_{0}^{(4)}(y), \\
& \theta_{1}^{\prime \prime}\left(y, C_{1}\right)=C_{1} M^{2} \operatorname{Br} u_{0}^{2}(y)+C_{1} B r\left(u_{0}^{\prime}(y)\right)^{2}+C_{1} \theta_{0}^{\prime \prime}(y),
\end{aligned}
$$




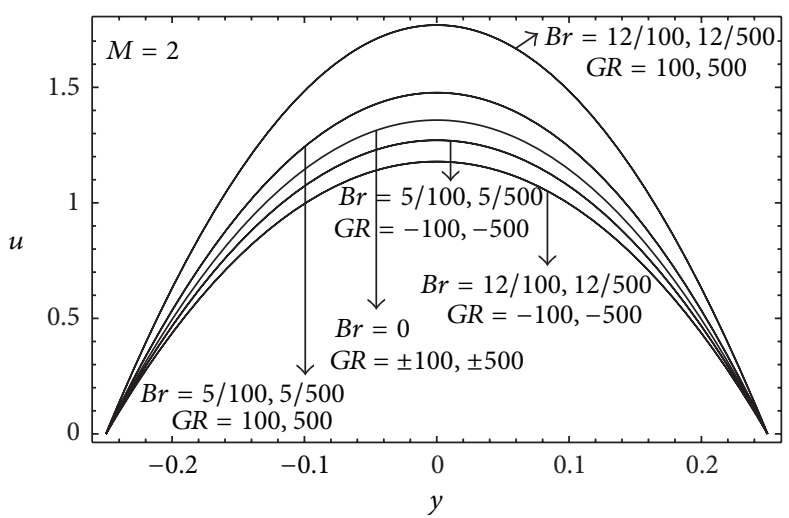

(a)

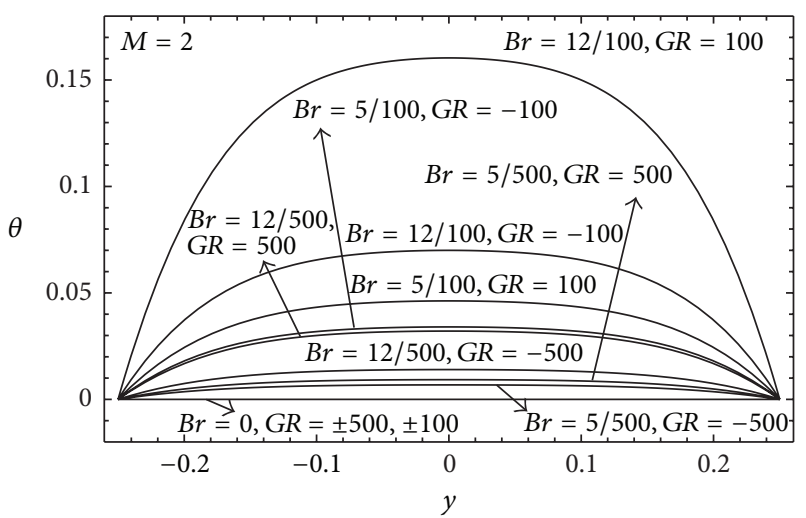

(b)

FIgURE 4: Plots of (a) $u$ and (b) $\theta$ versus $y$ in the case of symmetric heating for different values of $B r$ and $G R$.

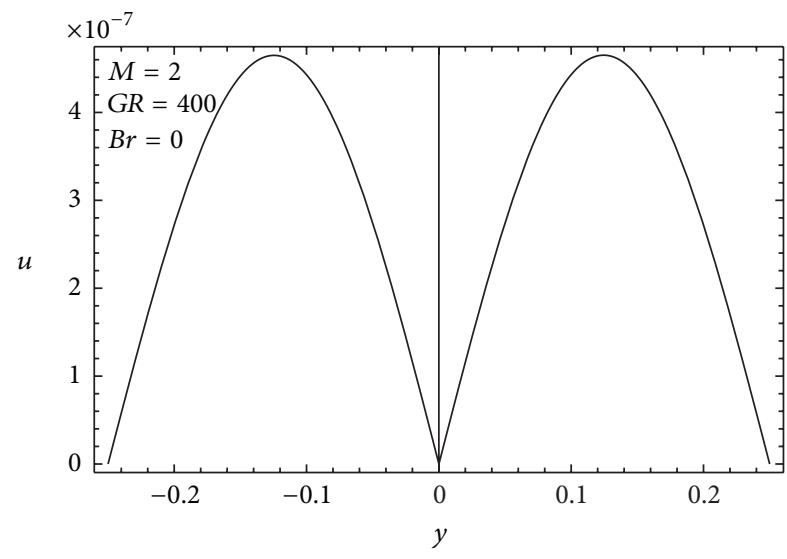

(a)

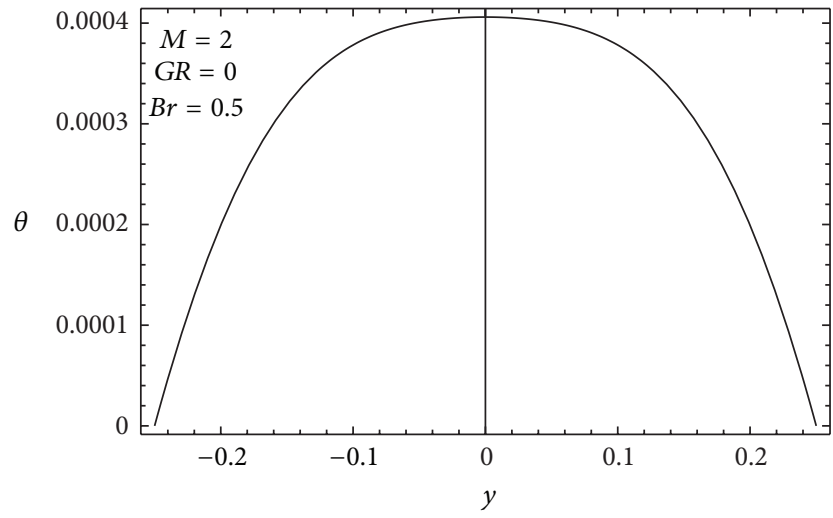

(b)

Figure 5: Plots of residual errors for (a) $u$ in the case $G R=400, B r=0$ and (b) $\theta$ in the case $G R=0, B r=0.5$ of asymmetric heating and $M=2$.

subject to the boundary conditions

$$
\begin{array}{ll}
u_{1}\left(-\frac{1}{4}\right)=0, & u_{1}\left(\frac{1}{4}\right)=0 \\
u_{1}^{\prime \prime}\left(-\frac{1}{4}\right)=0, & u_{1}^{\prime \prime}\left(\frac{1}{4}\right)=0 \\
\theta_{1}\left(-\frac{1}{4}\right)=0, & \theta_{1}\left(\frac{1}{4}\right)=0 .
\end{array}
$$

The second-order problem is

$$
\begin{aligned}
u_{2}^{(4)}\left(y, C_{1}, C_{2}\right)= & -C_{2} M^{2} u_{0}^{\prime \prime}(y)+C_{2} u_{0}^{(4)}(y) \\
& +u_{1}^{(4)}\left(y, C_{1}\right)-C_{2} M^{2} \operatorname{BrGR} u_{0}^{2}(y) \\
& -2 C_{1} M^{2} B r G R u_{0}(y) u_{1}\left(y, C_{1}\right) \\
& -C_{2} \operatorname{Br} G R\left(u_{0}^{\prime}(y)\right)^{2}+C_{1} u_{1}^{(4)}\left(y, C_{1}\right) \\
& -C_{1} M^{2} u_{1}^{\prime \prime}\left(y, C_{1}\right) \\
& -2 C_{1} B r G R u_{0}^{\prime}(y) u_{1}^{\prime}\left(y, C_{1}\right),
\end{aligned}
$$

$$
\begin{aligned}
\theta_{2}^{\prime \prime}\left(y, C_{1}, C_{2}\right)= & C_{2} M^{2} \operatorname{Bru}_{0}^{2}(y) \\
& +2 C_{1} M^{2} B r u_{0}(y) u_{1}\left(y, C_{1}\right) \\
& +C_{2} B r\left(u_{0}^{\prime}(y)\right)^{2}+2 c_{1} B r u_{0}^{\prime}(y) u_{1}^{\prime}\left(y, C_{1}\right) \\
& +C_{2} \theta_{0}^{\prime \prime}(y)+\left(1+C_{1}\right) \theta_{1}^{\prime \prime}\left(y, C_{1}\right),
\end{aligned}
$$

subject to the boundary conditions

$$
\begin{array}{ll}
u_{2}\left(-\frac{1}{4}\right)=0, & u_{2}\left(\frac{1}{4}\right)=0, \\
u_{2}^{\prime \prime}\left(-\frac{1}{4}\right)=0, & u_{2}^{\prime \prime}\left(\frac{1}{4}\right)=0, \\
\theta_{2}\left(-\frac{1}{4}\right)=0, & \theta_{2}\left(\frac{1}{4}\right)=0 .
\end{array}
$$




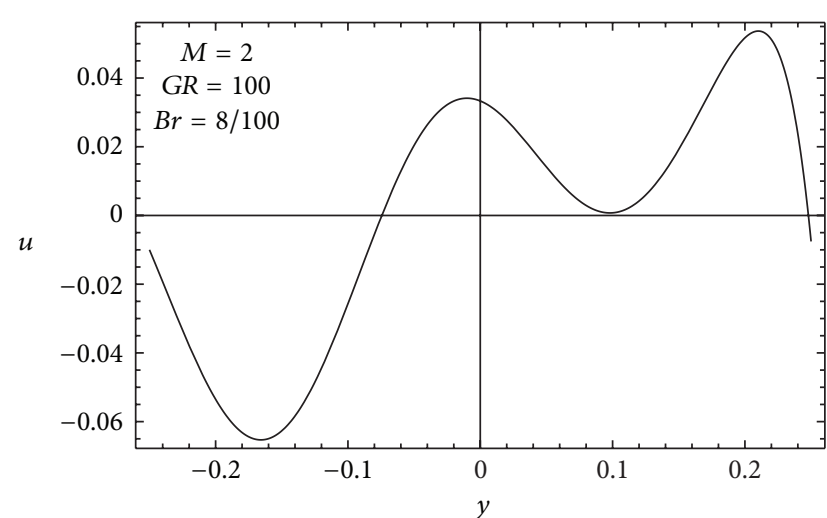

(a)

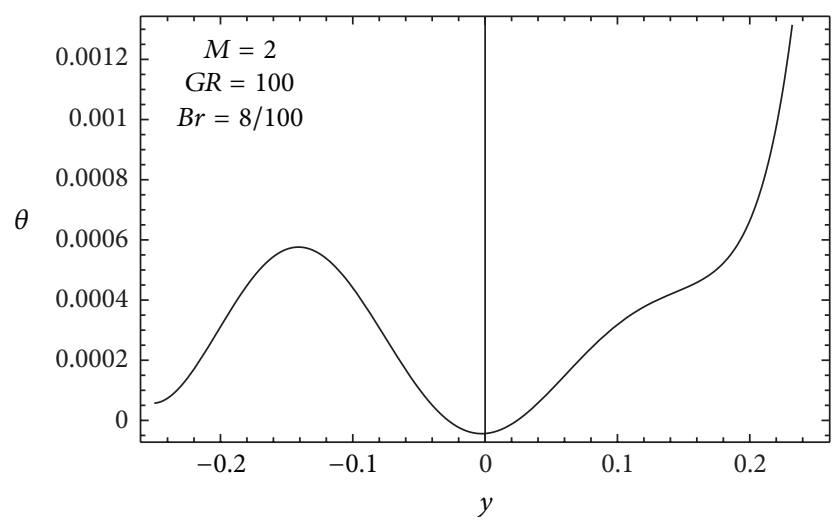

(b)

Figure 6: Plots of residual errors for (a) $u$ and (b) $\theta$ in the case of asymmetric heating for $G R=100, B r=8 / 100$ and $M=2$.

The third-order problem is

$$
\begin{aligned}
u_{3}^{(4)}\left(y, C_{1}, C_{2}, C_{3}\right)= & -M^{2} B r C_{3} G R u_{0}^{2}(y) \\
& -2 M^{2} B r C_{2} G R u_{0}(y) u_{1}\left(y, C_{1}\right) \\
& -C_{1} M^{2} B r G R u_{1}^{2}\left(y, C_{1}\right)+C_{3} u_{0}^{(4)}(y) \\
& +C_{2} u_{1}^{(4)}\left(y, C_{1}\right)-C_{3} B r G R\left(u_{0}^{\prime}(y)\right)^{2} \\
& -2 C_{2} B r G R u_{0}^{\prime}(y)-u_{1}^{\prime}\left(y, C_{1}\right) \\
& -C_{1} B r G R\left(u_{1}^{\prime}\left(y, C_{1}\right)\right)^{2} \\
& -C_{1} M^{2} u_{2}^{\prime \prime}\left(y, C_{1}, C_{2}\right) \\
& -C_{3} M^{2} u_{0}^{\prime \prime}(y)-C_{2} M^{2} u_{1}^{\prime \prime}\left(y, C_{1}\right) \\
& +C_{1} u_{2}^{(4)}\left(y, C_{1}, C_{2}\right) \\
& -2 C_{1} M^{2} B r G R u_{0}(y) u_{2}\left(y, C_{1}, C_{2}\right) \\
& +u_{2}^{(4)}\left(y, C_{1}, C_{2}\right) \\
& -2 C_{1} B r G R u_{0}^{\prime}(y) u_{2}^{\prime}\left(y, C_{1}, C_{2}\right), \\
\theta_{3}^{\prime \prime}\left(y, C_{1}, C_{2}, C_{3}\right)= & C_{3} M^{2} B r u_{0}^{2}(y) \\
& +2 C_{2} M^{2} B r u_{0}(y) u_{1}\left(y, C_{1}\right) \\
& +C_{1} M^{2} B r u_{1}^{2}\left(y, C_{1}\right) \\
& +2 C_{1} M^{2} B r u_{0}(y) u_{2}\left(y, C_{1}, C_{2}\right) \\
& +C_{3} B r\left(u_{0}^{\prime}(y)\right)^{2} \\
& +2 C_{2} B r u_{0}^{\prime}(y) u_{1}^{\prime}\left(y, C_{1}\right) \\
& +C_{1} B r\left(u_{1}^{\prime}\left(y, C_{1}\right)\right)^{2} \\
& 2 C_{1} B r u_{0}^{\prime}(y) u_{2}^{\prime}\left(y, C_{1}, C_{2}\right) \\
&
\end{aligned}
$$

$$
\begin{aligned}
& +C_{3} \theta_{0}^{\prime \prime}(y)+C_{2} \theta_{1}^{\prime \prime}\left(y, C_{1}\right) \\
& +\theta_{2}^{\prime \prime}\left(y, C_{1}, C_{2}\right)+C_{1} \theta_{2}^{\prime \prime}\left(y, C_{1}, C_{2}\right),
\end{aligned}
$$

subject to the boundary conditions

$$
\begin{array}{ll}
u_{3}\left(-\frac{1}{4}\right)=0, & u_{3}\left(\frac{1}{4}\right)=0 \\
u_{3}^{\prime \prime}\left(-\frac{1}{4}\right)=0, & u_{3}^{\prime \prime}\left(\frac{1}{4}\right)=0 \\
\theta_{3}\left(-\frac{1}{4}\right)=0, & \theta_{3}\left(\frac{1}{4}\right)=0 .
\end{array}
$$

Using the solution of (25)-(32) we obtain the following four-term approximate solutions for $u$ and $\theta$ by OHAM taking $p=1$ :

$$
\begin{aligned}
\widetilde{u}\left(y, C_{1}, C_{2}, C_{3}\right)= & u_{0}(y)+u_{1}\left(y, C_{1}\right) \\
& +u_{2}\left(y, C_{1}, C_{2}\right)+u_{3}\left(y, C_{1}, C_{2}, C_{3}\right), \\
\widetilde{\theta}\left(y, C_{1}, C_{2}, C_{3}\right)= & \theta_{0}(y)+\theta_{1}\left(y, C_{1}\right) \\
& +\theta_{2}\left(y, C_{1}, C_{2}\right)+\theta_{3}\left(y, C_{1}, C_{2}, C_{3}\right) .
\end{aligned}
$$

The explicit expressions for the individual terms of the approximate solutions are not given here for brevity. Taking the residual errors

$$
\begin{aligned}
R \tilde{u}\left(y, C_{1}, C_{2}, C_{3}\right)= & \widetilde{u}^{(4)}\left(y, C_{1}, C_{2}, C_{3}\right) \\
& -M^{2} \widetilde{u}^{\prime \prime}\left(y, C_{1}, C_{2}, C_{3}\right) \\
& -M^{2} \operatorname{GRBr} \widetilde{u}\left(y, C_{1}, C_{2}, C_{3}\right) \\
& -G R B r\left(\widetilde{u}^{\prime}\left(y, C_{1}, C_{2}, C_{3}\right)\right)^{2},
\end{aligned}
$$




$$
\begin{aligned}
R \tilde{\theta}\left(y, C_{1}, C_{2}, C_{3}\right)= & \tilde{\theta}^{\prime \prime}\left(y, C_{1}, C_{2}, C_{3}\right) \\
& +M^{2} \operatorname{Br}\left(\widetilde{u}\left(y, C_{1}, C_{2}, C_{3}\right)\right)^{2} \\
& -\operatorname{Br}\left(\widetilde{u}^{\prime}\left(y, C_{1}, C_{2}, C_{3}\right)\right)^{2},
\end{aligned}
$$

the optimal values of $C_{i}$ 's can be obtained. Table 1 shows some optimal values of $C_{i}$ for different values of $G R$ and $B r$.

In Figure 1 we compare our approximate four-term solutions (34) against the exact solutions (3) for the special case $B r=0$ and $M=2$ for several values of GR. The comparison of the special case $G R=0$ is shown in Figure 2 for $M=2$ and several values of $B r$. It is observed that our four-term OHAM solutions agree very well with the exact solutions. The general case of both $B r \neq 0$ and $G R \neq 0$ admits no explicit analytical solution. So, in Figures 3 and 4 we plot the four-term approximate OHAM solutions for several values of $B r$ and $G R$ in the case $M=2$ for both the asymmetric and symmetric heating conditions, respectively. The residual errors corresponding to selected cases of the solutions depicted in Figures 1 and 2 are presented in Figures 5(a) and 5(b), respectively. Finally, the residual errors for a selected case of Figure 3 are shown in Figure 6. Clearly, all the residual error plots suggest that the OHAM approximate solutions are accurate enough.

\section{Conclusion}

In this paper we have extended the applicability of OHAM for the first time to solve a nonlinear system of two-point BVPs that arise in a fluid flow problem. OHAM is relatively simple to apply. It was shown that, with a few terms, the OHAM is capable of giving sufficient accuracy. OHAM can be a promising tool for solving strongly nonlinear systems of equations.

\section{References}

[1] M. A. Noor and S. T. Mohyud-Din, "Variational iteration technique for solving higher order boundary value problems," Applied Mathematics and Computation, vol. 189, no. 2, pp. 19291942, 2007.

[2] M. A. Noor and S. T. Mohyud-Din, "A reliable approach for solving linear and nonlinear sixth-order boundary value problems," International Journal of Computational and Applied Mathematics, vol. 2, no. 2, pp. 163-172, 2007.

[3] M. A. Noor and S. T. Mohyud-Din, "Homotopy perturbation method for solving sixth-order boundary value problems," Computers \& Mathematics with Applications, vol. 55, no. 12, pp. 2953-2972, 2008.

[4] N. Herisanu, V. Marinca, T. Dordea, and G. Madescu, "A new analytical approach to nonlinear vibration of an electric machine," Proceedings of Romanian Academy Series A, vol. 9, no. 3, 2008.

[5] V. Marinca and N. Herisanu, "Application of optimal homotopy asymptotic method for solving nonlinear equations arising in heat transfer," International Communications in Heat \& Mass Transfer, vol. 35, pp. 710-715, 2008.
[6] V. Marinca, N. Herisanu, and I. Nemes, "Optimal homotopy asymptotic method with application to thin film flow," Central European Journal of Physics, vol. 6, no. 3, pp. 648-653, 2008.

[7] N. Herişanu and V. Marinca, "Explicit analytical approximation to large-amplitude non-linear oscillations of a uniform cantilever beam carrying an intermediate lumped mass and rotary inertia," Meccanica, vol. 45, no. 6, pp. 847-855, 2010.

[8] V. Marinca, N. Herişanu, C. Bota, and B. Marinca, "An optimal homotopy asymptotic method applied to the steady flow of a fourth-grade fluid past a porous plate," Applied Mathematics Letters, vol. 22, no. 2, pp. 245-251, 2009.

[9] M. Esmaeilpour and D. D. Ganji, "Solution of the JefferyHamel flow problem by optimal homotopy asymptotic method," Computers \& Mathematics with Applications, vol. 59, no. 11, pp. 3405-3411, 2010.

[10] M. Idrees, S. Islam, S. Haq, and S. Islam, "Application of the optimal homotopy asymptotic method to squeezing flow," Computers \& Mathematics with Applications, vol. 59, no. 12, pp. 3858-3866, 2010.

[11] V. Marinca and N. Herişanu, "An optimal homotopy asymptotic approach applied to nonlinear MHD Jeffery-Hamel flow," Mathematical Problems in Engineering, vol. 2011, Article ID 169056, 16 pages, 2011.

[12] S. Haq and M. Ishaq, "Solution of strongly nonlinear ordinary differential equations arising in heat transfer with optimal homotopy asymptotic method," International Journal of Heat \& Mass Transfer, vol. 55, no. 21-22, pp. 5737-5743, 2012.

[13] J. Ali, S. Islam, S. Islam, and G. Zaman, "The solution of multipoint boundary value problems by the optimal homotopy asymptotic method," Computers \& Mathematics with Applications, vol. 59, no. 6, pp. 2000-2006, 2010.

[14] J. Ali, S. Islam, H. Khan, and S. I. A. Shah, "The optimal homotopy asymptotic method for the solution of higher-order boundary value problems in finite domains," Abstract and Applied Analysis, vol. 2012, Article ID 401217, 14 pages, 2012.

[15] M. S. Hashmi, N. Khan, and S. Iqbal, "Numerical solutions of weakly singular Volterra integral equations using the optimal homotopy asymptotic method," Computers \& Mathematics with Applications, vol. 64, no. 6, pp. 1567-1574, 2012.

[16] J. C. Umavathi and M. S. Malashetty, "Magnetohydrodynamic mixed convection in a vertical channel," International Journal of Non-Linear Mechanics, vol. 40, no. 1, pp. 91-101, 2005. 


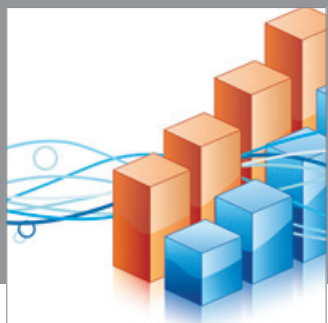

Advances in

Operations Research

mansans

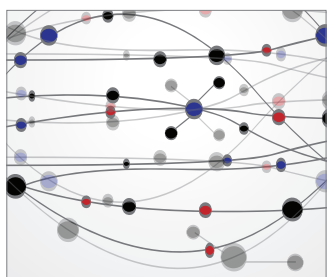

The Scientific World Journal
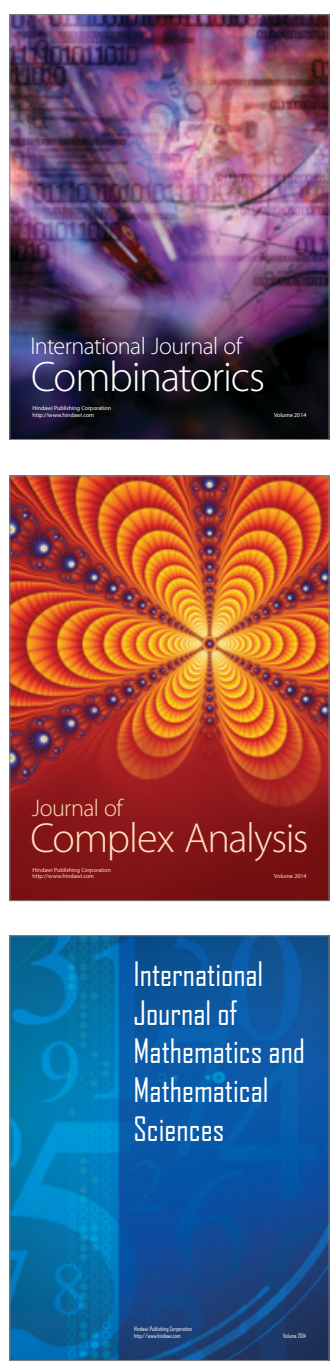
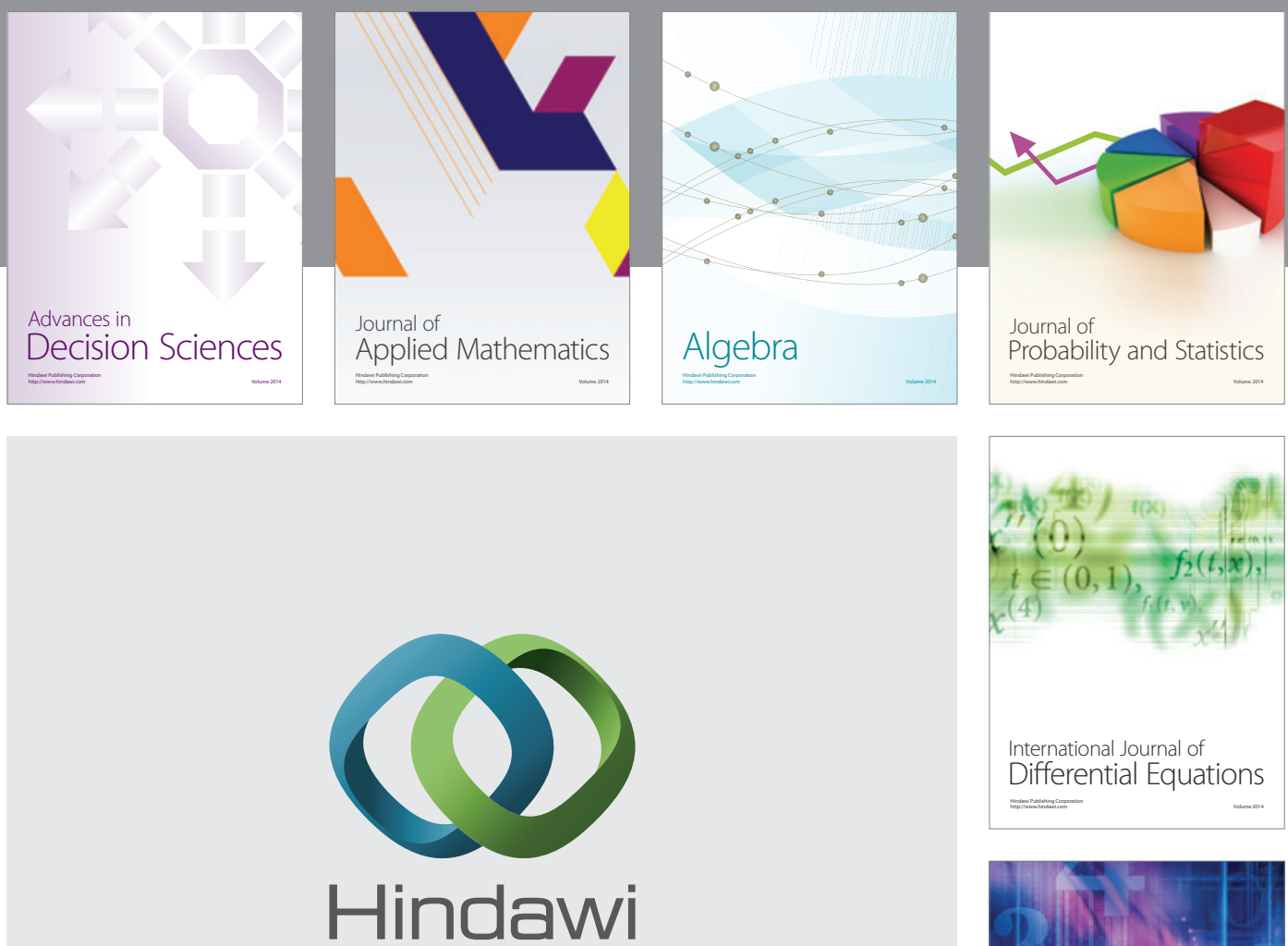

Submit your manuscripts at http://www.hindawi.com
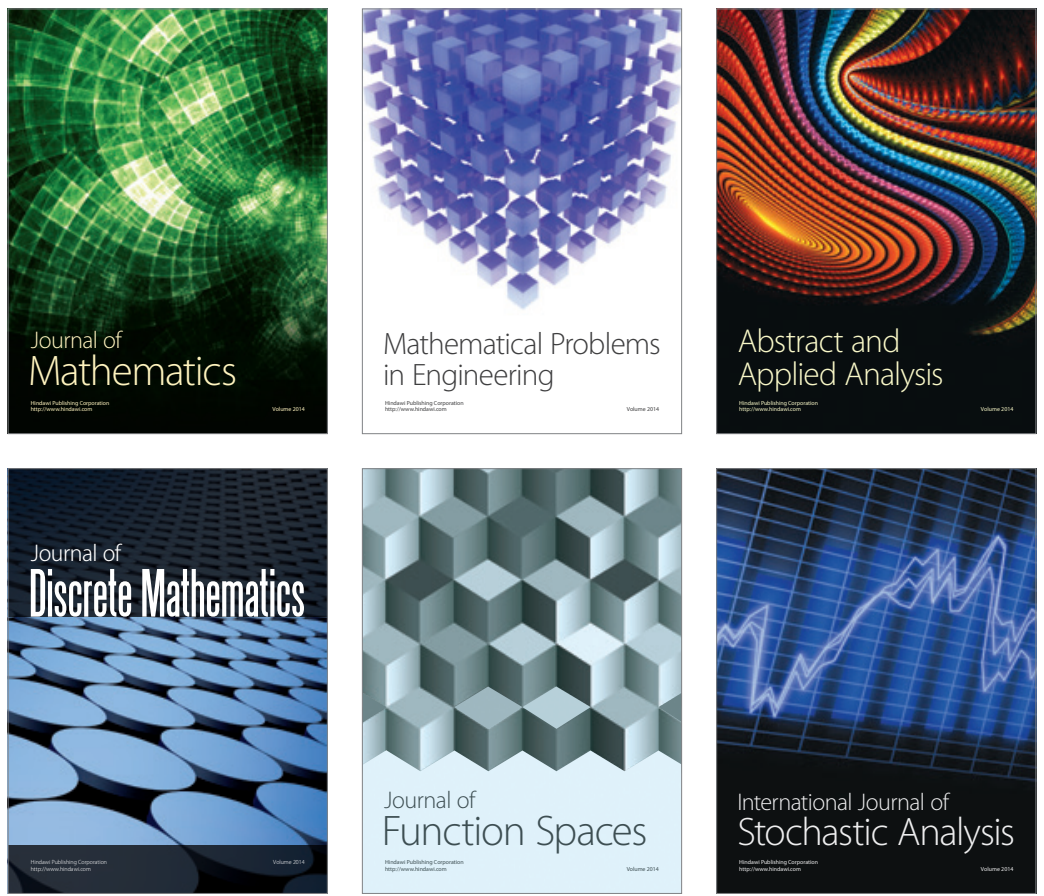

Journal of

Function Spaces

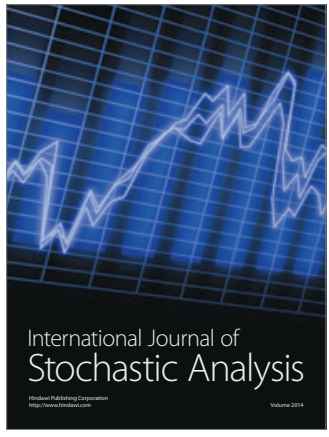

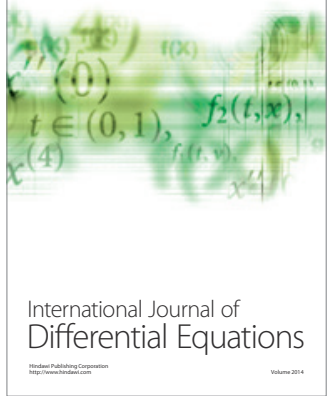
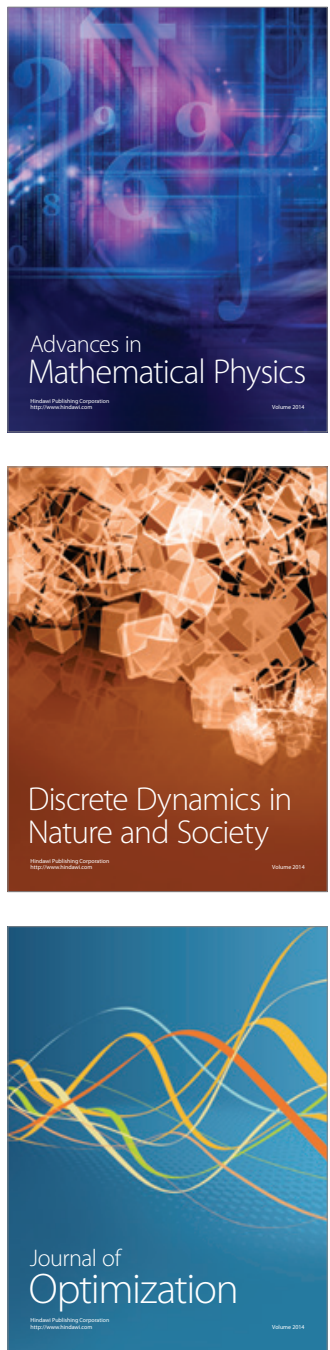